\title{
HOMBRES E IDEAS CONTEMPORÁNEAS
}

Roberto Escobar B.

La investigación y difusión del pensamiento de nuestros connacionales es una tarea -no sólo noble, sino particularmente positiva, pues de ella se desprenden las bases y esencias de nuestra identidad cultural y hace luz sobre los valores que ello encierra.

El libro: "Universidad Católica de Chile: Hombres e Ideas (1900-1950)" de los autores: Luis Celis, Jaime Caiceo, Elena Sánchez, Sara López y Fernando Aliaga", que ofrece la Universidad Católica es un aporte destacado en este campo ya que rescata la idea de que esa Universidad ha sido el centro de un proceso de irradiación intelectual importante durante el período 1900-1950.

Lo que no queda claro es que el contenido de esa irradiación haya sido específicamente contrario a las posiciones liberales $y / o$ positivistas de otras instituciones $y$ academias.

Si bien la vida nacional ha sido "agitada" durante el primer medio siglo, to ha sido básicamente en lo político y económico, mientras que el pensamiento filosófico y científico ha seguido un cauce mucho más seguro y más constante.

Habría que distinguir entre las corrientes de pensamiento ético, al menos tres:

a) Estudios éticos que proponen modelos, en general reinterpretando la filosofía griega para la realidad americana.

b) Consideraciones éticas que se dirigen desde y hacia la Filosofía Cristiana.

c) Enfoques éticos a partir de la acción social, el derecho y la cultura.

Publicado por Editorial Facultad de Educación Universidad Católica de Chile, Santiago. 1988.

Ver, en más detalle Introducción en Estudios de Ética (1829-1981), Sociedad Chilena de Filosofía,

Santiago. 1984. 
Si bien no se ve tan evidente que entre las tres corrientes señaladas haya habido un debate controversial y excluyente - hay que senalar que los autores: Finlayson, Gandolfo, Lira (Osvaldo) y Martínez pertenecen de lieno a la corriente cristiana b) así como Larson; los otros pensadores del "Área Educativo-Social", en la obra que comentamos, pertenecen de lleno a la corriente c) los dos Vives y Hurtado. A Lira (Pedro) lo identificaría con la corriente a), así como a Eyzaguirre.

Puede comentarse que hasta 1930 la Universidad de Chile tuvo una Facultad de Teología, uno de cuyos Decanos fue Rafael Fernández Concha, cultor del tomismo y cuya "Filosofía del Derecho" fue reeditada por Francisco Vives en 1966. De modo que no hay debate entre ambas universidades, a nivel ideológico hasta 1938 en el Frente Popular.

Por cierto que todo intento de clasificación de ideas y pensadores, encierra el peligro de falsear intenciones y obscurecen, muchas veces, el verdadero valor original de ellos.

Para evitarlo es necesario destacar la presencia de la Universidad Católica en el medio nacional como medio de difusión de un humanismo que pretendió -entre 1900 y 1950 influir en todos los ámbitos de la vida pública, y sus pensadores actuaron en un campo más general que la pura Academia.

La relación entre la docencia universitaria, como actividad parcial, con la práctica de profesiones y cargos públicos, llevó hacia la U.C. a muchos hombres públicos que beneficiaron a la Academia con una relación exterior e irradiaron el pensamiento universitario en la vida nacional.

Esta situación nacida de la estrechez económica de la U.C. tuvo la virtud de fortalecer una formación y así-inesperadamente- elevar el nivel profesional de una enseñanza.

La lectura del libro que comento me sugirió a este respecto algunos nombres de personas que calzan dentro del panorama que describo y cuya obra reseño a continuación como un complemento a la obra.

En el campo del Derecho, la Universidad Católica no sólo cuenta con el aporte de Pedro Lira sino que es necesario rescatar la actividad de Francisco Vives, en esa disciplina con su "Introducción al estudio del Derecho" (1936) y recordar a Fernández Concha, ya mencionado.

También en campo del Derecho Internacional la Universidad Católica contó con Alberto Cruchaga Ossa (1889-1947) uno de los internacionalistas más destacados de nuestro pais en el período estudiado, seguidor del americanismo de Alejandro Álvarez y quien se desempeñó durante casi toda una vida como Asesor Jurídico de nuestra Cancilleria. De él dice Jaime Eyzaguirre:

"Era el señor Cruchaga hombre ilustrado entre los más, e incansable obrero de la inteligencia. Sobrio y recoleto, huia del tráfago agitado y de las vanidosas exhibiciones, para refugiarse en la meditación. Alli estaba su solaz y esparcimiento. En las 
pocas horas libres que solian concederle sus tareas funcionarias, exploraba archivos, compulsaba libros y periódicos viejos y anotaba prolijo el fruto de su investigación. Llegó, de esta manera, a ser increible el acervo de sus conocimientos e irreemplazable en la Cancillería su docto consejo.

Su formación teórica y práctica del Derecho Internacional la puso en evidencia en su cátedra de la Universidad Católica de Chile; en sus memorables dictámenes de Asesor Jurídico del Ministerio de Relaciones Exteriores, que lo sitúan en la alta línea fijada por el sabio Bello, y en numerosas monografias como La nacionalidad y los modos de adquirirla, La inmunidad diplomática, La zona de seguridad ainericana, La codificación del Derecho Internacional en la Conferencia Panamericana de Lima, Relaciones entre el Derecho Internacional en la Conferencia Panamericana de Lima, Relaciones entre el Derecho Internacional y las legislaciones nacionales.

La versación histórica del señor Cruchaga corrió pareja a sus conocimientos juridicos. Cuando en 1933 se echaron las bases de la Academia Chilena de la Historia, su nombre figuró entre los fundadores. Colaboró desde entonces con cierta frecuencia en su Boletín sobre temas de historia diplomática, como ya lo estaba haciendo en la Revista Chilena que, por entonces, publicaba de manera oficial la Cancilleria".

Entre sus obras se cuenta: "Los primeros años del Ministerio de Relaciones Exteriores" (1919). "Ercilla y el Derecho Internacional", "Estudios de Historia Diplomática Chilena" (1962) y numerosos ensayos en casi todos los Boletines de la Academia durante su vida.

La versación y docencia de Cruchaga fundaron una verdadera doctrina de resonancia panamericana a través de su participación en los trabajos de codificación del Derecho Internacional y por medio de su coedición, ampliación y profundización del texto "Derecho Internacional", publicado por Miguel Cruchaga Tocornal, en 1899.

También dentro del campo Jurídico es necesario mencionar a Julio Philippi Izquierdo quien empieza a participar activamente en la vida académica en la década del 40, publicando "Del Derecho individualista a un Derecho Humano" (1940), "La Teoría de la institución" (1942), "Notas sobre la posición de la persona ante la sociedad" (1951) y numerosos aportes anteriores a 1950, que lo colocan entre los humanistas más completos y destacados del país.

Una persona que creo que no debe ser olvidada es Enrique Valenzuela, quien junto a Francisco Vives colaboraron con Carlos Casanueva en la Dirección de la Universidad.

Valenzuela se interesaba por desarrollar estudios sistemáticos de Filosofía en la Universidad Católica y a él se deben los cursos abiertos que se dictaron en la década del 40 a cargo del Padre Escudero (agustino) y el Padre Latorre (dominico), con gran éxito. Al mismo tiempo, con la ayuda de Torcuato Luca de Tena licenciado 
español de igual nombre que su padre, entonces Embajador de España en Chile, emprende la creación de cursos formales de Filosofía también en los años 40.

En 1948 se fundó la Sociedad Chilena de Filosofía y Enrique Valenzuela aparece como uno de los fundadores y durante sus primeros años anima el encuentro entre filósofos de diferentes tendencias, dentro de la mayor cordialidad.

Si bien no dejó muchos escritos, su gestión personal hizo mucho en abrir la Universidad Católica hacia un eclecticismo más acorde con los tiempos y con los principios de una actividad puramente especulativa en la filosofía, no vinculada a la aplicación al Derecho, la Historia, la Educación o la Cuestión Social.

Termino felicitando a los autores de "Universidad Católica de Chile: Hombres e Ideas (1900-1950)", rogándoles comprender que el solo propósito de mis comentarios es destacar la importancia de libros de rescate y difusión de las ideas nacionales y sólo agrego algunos gramos de arena al sólido trabajo que ellos ya han realizado. 